\title{
A Descriptive Study to Assess Wellbeing, Quality of Life and Satisfaction of Omani Patients with Chronic Wounds
}

\author{
Jansi Rani Natarajan ( $\sim$ Jannat@squ.edu.om ) \\ Sultan Qaboos University \\ Mickael Antoine Joseph \\ Sultan Qaboos University \\ Rashid Mohammed Al Alawi \\ Royal Hospital \\ Taimoor Al Balushi \\ Khoula Hospital \\ Ibrahim Al Alawi \\ Armed forces Hospital \\ Suad Moosa Al Junaibi \\ Oman college of health sciences \\ Anitha Nesa Thanka John \\ Sultan Qaboos University \\ Laila bint Darwish Al Balushi \\ Oman college of health sciences \\ Issa Sulaiman Al Ismaili \\ Armed forces Hospital \\ Moath Shummo \\ Khoula Hospital
}

\section{Research Article}

Keywords: Chronic wound, wellbeing, quality of life, satisfaction, impact

Posted Date: December 29th, 2021

DOI: https://doi.org/10.21203/rs.3.rs-1173016/v1

License: (c) (i) This work is licensed under a Creative Commons Attribution 4.0 International License.

Read Full License 


\section{Abstract}

Background: A chronic wound is one that has failed to proceed through the normal phases of wound healing in an orderly manner. Chronic wounds are a common problem around the world. They can be distressing to the patients causing physical, social and emotional damage such as decreased activities of daily living, pain, discomfort, unpleasant odor, and insomnia. Wellbeing, quality of life and satisfaction of these patients with chronic wounds can be impaired by a complex set of aspects. The purpose of this article is to describe the impact of chronic wounds on the wellbeing, quality of life and satisfaction of Omani patients with chronic wounds.

Methods: This is a descriptive cross-sectional study of 275 patients with chronic wounds attending three tertiary care hospitals in Muscat city, Sultanate of Oman. Adult patients of 18 years and above with wounds of duration of more than 4 weeks were chosen by consecutive non-probability sampling. A pretested, semi-structured self-reported questionnaire was provided to each patient to complete. Data was analysed using SPSS IBM version 23.

Results: The average age of the patients was $47.13 \pm 16.917$ and the majority of them $(64.7 \%)$ were males. Most of them (29.1\%) had diabetic ulcers and $45.8 \%$ of them presented with mildly severe wounds based on Bates-Jensen wound assessment scale. Patients with chronic wounds reported a poor wellbeing scores $(M=10.47, S D=1.813)$, moderate quality of life $(M=5.22, S D=2.388)$ and satisfaction scores $(M=6.89, S D=2.388)$. Significant mean differences were reported with age, gender, educational level, and type of wound at $p<.05$ levels.

Conclusion: These findings demonstrated that chronic wounds could influence the wellbeing, quality of life and overall satisfaction with the quality of life of patients suffering with it. These results also suggest a need to pay increased attention by the healthcare providers to the patients suffering from chronic wounds on the aspects of wellbeing and quality of life along with treating the physical symptoms.

\section{Background}

Chronic wounds are distressing conditions that can impact all facets of a patient's health-related quality of life, in particular well-being and satisfaction [1]. Chronic wounds are defined as the wounds which "fail to proceed through the normal phases of wound healing in an orderly and timely manner" [2]. The elderly and patients with comorbidities are the most affected by these chronic wounds which most commonly include arterial and venous leg ulcers, diabetic foot ulcers and pressure ulcers [3]. Chronic wounds are considered a widespread problem across the globe [4]. In a systematic review of the literature, Martinengo L, Olsson M, Bajpai R, Soljak M, Upton Z, Schmidtchen A, Car J and Järbrink K [5] found that the point prevalence of chronic wounds is approximately $0.2 \%$ and the lifetime prevalence is around $1 \%$. However, many studies have shown that although chronic wounds present a significant burden on patients, they are widely underreported $[6,7]$. An approximate $2 \%$ of the total American population is affected by chronic wounds, which is between 2.5 - 4.5 million patients [8]. The prevalence is higher in the United 
Kingdom where Phillips CJ, Humphreys I, Fletcher J, Harding K, Chamberlain G and Macey S [9] have shown that $6 \%$ of the Welsh population is affected by chronic wounds. In the Arab world in general and in Oman in particular, the prevalence of chronic wounds is unknown. However, one could expect a significant number of the Arab population is experiencing or will experience chronic wounds at a certain point. This is even more probable when considering that the prevalence of diabetes is the highest worldwide in this region which could eventually lead to diabetic ulcer in many patients [10].

Chronic wounds can seriously affect patients' wellbeing and quality of life [11]. Quality of life differs from well-being. While well-being is the subjective emotional response the patient has over their wound, its treatment and the outcome of the wound; quality of life is the evaluation that a patient makes about the impact of a disease on their everyday life [12]. Patients with chronic wounds have a higher level of anxiety when compared to healthy patients [13]. This anxiety affects their well-being and stems from worry, disappointment, frustrations, the wound's uncertain nature of healing and the threat of relapse [11]. Understanding chronic wounds patients' wellbeing allows health care professionals to focus on the worries of the patient and to deliver a holistic treatment [14].

Moreover, patients with chronic wounds have difficulties coping with their injuries resulting in body image problem, low self-esteem, a restricted social life, and professional and financial burdens [15]. These aspects have great repercussions on the health-related quality of life of the patients. A low quality of life has been shown to cause poor health outcomes and increase the risk of comorbidity decreasing the patients' life expectancy [16].

The World Health Organization predicted that the proportion of people aged 60 and above will double by 2050 , which could undoubtably mean that the burden of chronic wounds will only increase, and countries will face a difficult task preparing their health care system [17]. Therefore, we need to understand the impact of chronic wounds on patients' wellbeing, quality of life, and satisfaction in order to find coping strategies to improve those variables. Although it is well known that chronic wounds negatively impact patients' well-being, health-related quality of life, and satisfaction, patients' attitudes and opinions may differ between countries and cultures. The concepts of well-being and quality of life are known to be particular to each individual, changes over time, and depends on culture and context [18]. Therefore, assessing the wellbeing and quality of life of Omani patients who suffer from chronic wound is primordial to offer a better treatment, a holistic one with centring not only on wound healing.

The Cardiff Chronic wound scale is a questionnaire containing seven items focusing on patients' wellbeing in relation to the chronic wound, and more particularly tackles the anxiety about the impact and the result of the wound [14]. A new version of the questionnaire was developed and an overall rating of health-related quality of life using a 10-point scale was incorporated, as well as a rating of patient's satisfaction.

To our knowledge, no studies have addressed well-being, quality of life, and satisfaction of Omani patients with chronic wounds. Yet, failure to address these important measures can negatively impact 
patient outcomes. Therefore, the aim of this cross-sectional study is to assess the impact of chronic wounds on these three variables in Omani patients.

\section{Methods}

\section{Study design and settings}

This was a cross-sectional study conducted in three tertiary hospitals in Muscat, Oman from June 2020 to December 2020.

\section{Participants}

A total consecutive sampling of 275 patients meeting the inclusion criteria were recruited from the wound care clinics of the three tertiary care hospitals (Sultan Qaboos University hospital, Royal Hospital and Khoula hospital) of Muscat, Oman. A sample size of 300 individuals was determined by $\mathrm{G}$ power analysis and 275 participants (91.6\%) responded to the self-reported questionnaire. Inclusion criteria consisted of adult patients of 18 years and above suffering from chronic wounds (healing was arrested in any wound healing stages for more than four weeks duration) and participants were excluded if they had mental illness, dementia, or they had suffered a major traumatic event in the six months prior to the study.

\section{Ethical consideration}

Ethical approval was received from the research and ethics committee of Sultan Qaboos University and respective hospitals. All participants gave their informed consent prior to data collection. Both the researchers and the participants agreed to use the data for scientific research purposes only. All personal identifications of patients remained anonymous to ensure that there was no violation of privacy. Data confidentiality was maintained, and all physical data files were kept in locked cabinets in the researcher's office. All the signed informed consent forms with the respondent's details were stored and locked separately from the data. Confidentiality was also maintained by assigning code numbers instead of names to the data files.

\section{Data collection and analysis}

Three research assistants (RAs) who were working as senior nurses in the hospitals were recruited and trained on ethical considerations in recruiting the participants for the study and data collection. Information about the patients with chronic wounds who were admitted to the hospital wards for treatment or visiting the outpatient department were accessed from the hospital registry. A consecutive sample from the list was approached by the RAs and the purpose of the study and voluntary nature of participation was explained. After obtaining their informed consent, they were taken to a separate room for a data collection interview which lasted for 15 minutes. Participants were given the self-reported questionnaire and those who required assistance were helped by the RA. A pilot study was conducted with 20 patients who were excluded from the target study sample. This assured the reliability and validity of the questionnaires. 


\section{Instruments used in data collection}

The self-reported questionnaire consisted of four parts. The first part consisted of socio-demographic details like age, gender, educational level, marital status, monthly income, occupation. The second part included clinical details like type of wound, presence of co-morbidities and treatment, which were accessed from the medical records of patients and filled in by the RA. The third part consisted of the Bates-Jensen wound assessment tool to assess the severity of the wound with the help of 13 items ranging from 1 to 5 with specific characteristics [19]. Wound assessment was made through observation by the research assistants who were trained to use the Bate-Jensen wound assessment tool. The severity scores were interpreted as follows: $13-20$ as minimum severity, $21-30$ as mild severity, $31-40$ as moderated severity and 41-65 as extremely severe wound. In addition, the fourth part uses the Cardiff wound impact scale (CWIS) to assess the wellbeing and quality of life of the participants and satisfaction of overall quality of life of the participants. Wellbeing was assessed with seven items in a Likert scale of 1 to 5 ( $1=$ strongly disagree, $2=$ disagree, $3=$ not sure, $4=$ agree and $5=$ =strongly agree). The scores were combined as 1 (strongly disagree, disagree and not sure) and 2 (agree and strongly agree). The total scores ranged from 7 to 14 with higher scores indicating poor wellbeing. One item was reverse scored. The participants were asked to rate their overall quality of life in the preceding week on a numerical rating scale of 0 to 10 , ranging from the worst possible to the best possible. The participants were also asked to rate their satisfaction with the overall quality of life in the preceding week on a numerical rating scale of 0 to 10 , ranging from not at all satisfied to very satisfied. The internal consistency of the CWIS subscales had a standardized Cronbach's alpha range from 0.715 to 0.797 [20] and in our study the Cronbach's Alpha for the wellbeing scale was 0.726 .

\section{Data analysis}

SPSS Statistics (IBM Corp. Released 2015. IBM SPSS Statistics for Windows, Version 23.0. Armonk, NY: IBM Corp.) was used for data entry, data cleaning, and data analysis. The data was audited for accuracy by two investigators. A probability of $<0.05$ was considered statistically significant for all tests. Descriptive summaries of sociodemographic and clinical characteristics (means, standard deviations, frequencies, percentages) were used to describe the sample. Comparison of wellbeing, health-related quality of life and satisfaction with quality of life scores with demographic and clinical variables were done using independent $t$ test and analysis of variance. Pearson correlation was used to identify the relationship between wellbeing, quality of life and satisfaction.

\section{Results}

Among the 275 participants who responded, 87 (31.6\%) were in the age group of 31 to 45 years and 178 $(64.7 \%)$ were males. Overall, $179(65.1 \%)$ had lower level of education and $244(88.7 \%)$ had a monthly income of less than 1000 Omani riyals. The majority 190 (69.1\%) of them were married and $102(37.1 \%)$ were employed. 
Regarding the type of wound, 80 (29.1\%) had diabetic ulcers followed by 61 (22.2\%) with surgical wound ulcers and 51 (18.5\%) had pressure ulcers. Most of them, 187 (68\%), had co-morbidities like diabetes, hypertension, stroke, and heart diseases and 130 (47.8\%) were treated with dressing.

Wound severity was classified with the help of Bates-Jensen wound tool as: scores of 13 to 20 was considered as minimum, $21-30$ as mild, 31-40 as moderate, and $41-65$ as extreme severity. Many of the patients $126(45.8 \%)$ presented with mildly severe wounds followed by $70(25.5 \%)$ with moderately severe wounds.

Table 2 revealed the perception of wellbeing of patients with chronic wounds. The total scores ranged from 7 to 14 with higher scores indicating poor wellbeing. The mean and SD of wellbeing scores of the participants was $10.47 \pm 1.813$. There was significant difference with chi-square analysis between those who strongly disagreed and those who strongly agreed with the statements at $p<.05$. The patients with chronic wounds agreed and strongly agreed for the following items: "I feel anxious about my wound" (68\%), "I feel frustrated at the time it is taking for the wound to heal" (59.3\%), "The appearance of the wound site is upsetting" (65.8\%). They strongly disagreed or disagreed for the following items: "I am confident that the wound I have will heal" (85.5\%) and "I worry that I may get another wound in future" (56.4\%).

As seen in figure 1, when the patients were asked to rate their quality of life and satisfaction with the overall quality of life in a visual analogue scale of 0 (worst possible) to 10 (best possible), the mean and SD were $5.22 \pm 2.508$ and $6.89 \pm 2.388$ respectively.

The results of association of wellbeing scores, quality of life and satisfaction scores with demographic and clinical profile of the patients with chronic wounds are presented in table 3. A one-way analysis of variance showed that the wellbeing mean scores and satisfaction with overall quality of life scores were significantly different with type of wounds, $F(3,271)=4.49, p=.004$, and $F(3,271)=4.35, p=.005$. Post hoc comparisons using Tukey HSD showed that patients with pressure ulcers had worse wellbeing scores $(M=11.16)$ and low satisfaction with overall quality of life $(M=5.90)$ than patients with other type of wounds. There was also a significant mean difference found between the age group and the wellbeing scores, $F(3,271)=3.47, p=.017$. Post hoc comparisons revealed that patients above 60 years reported poor wellbeing scores $(M=11.09)$ than other age groups. There was also a significant mean difference found between the educational levels of patients and the wellbeing scores. Patients with lower educational levels had poor wellbeing $(M=10.64)$ than the patients with higher educational levels $(M=10.15), t(273)=2.18, p=.03$. There was a significant difference in the perception of wellbeing between male and female patients with chronic wounds, $t(273)=-2.71, p=.007$. Female patients had reported poor wellbeing $(M=10.87)$ compared with the male patients $(M=10.25)$. There were no significant differences in the mean scores of wellbeing, quality life and satisfaction of overall quality of life with other demographic and clinical characteristics of the participants.

As presented in table 4, there was a significant positive correlation between quality of life and satisfaction with overall quality of life of patients with chronic wounds, $(r(275)=.44, p<.001)$. Negative 
correlations existed between wellbeing scores and the quality of life, $(r(275)=-.28, p<.001)$ and satisfaction with overall quality of life, $(r(275)=-.30, p<.001)$.

\section{Discussion}

Patients with chronic wounds face challenges and obstacles in several aspects of their daily living. The presence of chronic wounds tends to lead a person to negative feelings of wellbeing in physical, emotional and social spheres of life; as well, it can affect the quality of life and satisfaction with their overall quality of life.

In the present study, Omani patients above 31 years old with chronic wounds accounted for more than $80 \%$ of the participant population with males being the majority of around $65 \%$. A study on American patients have revealed that male gender and old age are risk factors for chronic wounds [21]. This result is widely observed and most probably due to the fact that men and the elderly are at higher risk for type 2 diabetes, accidents, and vascular diseases which increase their risks for chronic wounds more than females and younger adults [22]. Moreover, the better management of diseases, especially infectious, cardiovascular and cancer in the older population increased the survival rate, and consequently the prevalence of chronic wounds in the elderly [23].

Diabetic ulcers were the most common types of wounds in almost $30 \%$ of patients while surgical wound ulcers were the second. The Arab region is estimated to have the highest diabetes mellitus prevalence worldwide and reports have shown a recent increase in the prevalence among Omani nationals, and this prevalence is expected to increase significantly in the upcoming years [24]. This might explain why diabetic ulcers the most common type of wounds are observed in this study.

A study in Oman revealed that the level of knowledge about chronic wounds in general and Pressure ulcers wound is relatively low among nurses. Most Omani nurses were unfamiliar with the management of wounds as they lacked knowledge and skills [25]. The majority of the participants expressed a low wellbeing level with the majority reporting not being confident that the wound will ever heal, and many felt anxious about their wound. The wellbeing of a patient with chronic wound should be given more attention by empowering the health care providers caring for them in the clinical setting.

Several factors negatively influenced wellbeing in patients with chronic wounds including female gender, older age, low educational level, and the type of wounds. In this study, the predominant level of education was elementary and high school education. This is in line with the studies carried out in other places [26, 27]. Lower levels of education may lead to extended recovery time because of lack of understanding of self-care management and non-adherence to the treatment protocol.

In Research, both quality of life and wellbeing are used interchangeably although being related but not the same. Well-being is an emotional response to health circumstances, whereas health-related quality of life refers to how patients evaluate what they perceive to be happening in terms of your health. Participants in this study expressed a relatively low level of quality of life and low level of satisfaction 
with their overall quality of life. The findings are similar with another research conducted across the world [27-29]. One possible reason could be due to a non-optimal care. A study in Oman revealed that the level of knowledge about chronic wounds in general and Pressure ulcers wound is relatively low among nurses. Most Omani nurses were unfamiliar with the management of wounds as they lacked knowledge and skills [25]. Patients with pressure ulcers reported lower satisfaction with overall quality of life. Pressure ulcers are a common chronic wound affecting approximately 1 in 7 hospital and 1 in 20 community patients $[30,31]$. Many patients with pressure ulcers have viewed the ulcer as "the worst thing that can happen". The impact of pressure ulcers on an individual is tremendous, ongoing, and unique. Research focussing on the impact of pressure ulcers is limited and it presents the need to understand their issues and challenges. A success story of a hospital in Abu Dhabi, which implemented risk assessment and prevention pathway protocols, reported the reduction in prevalence of pressure ulcers [32] and improvement in satisfaction of quality of life of patients can be trailed in the clinical setting of Oman too.

It was also observed that female patients perceived that their wellbeing was adversely affected more than males. It is well established in the literature that women are more prone to negative health and wellbeing than men [33]. Existing data reveals that women with diabetes feel that they are not supported by the family members, friends and health care providers [34]. In a Gulf country like Oman where the role of women is mostly confined to the care of the home and family, chronic wounds could greatly affect their caring role. Franks MM and Stephens MAP [35] showed that women might feel guilty if they are not able to meet their care duties and responsibilities. Women are found to be using negative coping styles such as emotion-focussed, which can lead to poor emotional wellbeing [36]. More research focussing on the emotional aspects and coping mechanisms of women with chronic wound could shed extra light in this area.

When the factor "quality of life" is increased, the satisfaction level on quality of life is also increased. Both are reported to be low when the wellbeing of the patient is reduced in this study. The Sultanate of Oman is a beautiful country with the culture as rich as any other Arab nation encourages the individual to follow their religious practice of faith in God in all situations. This religious coping is interpreted as a strategy used to deal with uncertainties associated with the disease and overcome crises [37]. Holistic care of patients with chronic wounds through a multi-disciplinary team approach can improve the wellbeing as well the quality of life and satisfaction of these patients.

\section{Limitations}

One of the major limitations in our study is the consecutive sampling approach that relied on research assistant nurses to recruit participants. This limitation could lead to the recruitment of a sample that is not representative of the population because patients who are more prone to participate are those who are chronically ill [38]. This was true for our population where most participants have more than one comorbidity. This study was conducted among Omani population attending the three tertiary care 
hospitals in Muscat city which leaves it open to cultural bias. The data was collected using a selfreported questionnaire which makes it subjective, and this may affect the accuracy and precision.

\section{Conclusions}

To attain optimal patient care, the health care professional must understand the impact of chronic wounds on the wellbeing, quality of life, and satisfaction of patients. Living with chronic wounds can cause emotional distress which is known to impact the physiologic process of wound healing [39]. Moreover, interventions tackling wellbeing have been shown to improve healing of both acute and chronic wounds [39]. Therefore, having a greater focus on patients' wellbeing could be key to offering better health outcomes. Coping strategies such as social support networks which provide emotional help need to be developed especially tackling new patients with chronic wounds. Hospitals should provide support for patients to explore new relaxation techniques, which might improve patients' wellbeing and enhance their health-related quality of life.

\section{Declarations}

Ethical approval and consent to participate - Written informed consent with the signature of the participant was obtained before collecting data.

Consent for publication - All the authors have agreed for publication

Availability of supporting data - If needed it will be made available

Competing interests - None

Funding - Internal Grant of the Sultan Qaboos University conducting the research IG/CON/FACN/20/01

Author's contributions - First and second author contributed from the conception of the study to manuscript preparation. All other authors contributed in data collection, data entry, data analysis, reviewing and revising the manusctript.

Acknowledgments - The researchers want to thank the three research assistants who assisted with data collection and entry. Special note of thanks to our patients who had consented to participate in the study.

\section{References}

1. Vogt TN, Koller FJ, Santos PND, Lenhani BE, Guimarães PRB, Kalinke LP: Quality of life assessment in chronic wound patients using the Wound-QoL and FLQA-Wk instruments. Investigacion $y$ educacion en enfermeria 2020, 38:e11.

2. Frykberg RG, Banks J: Challenges in the Treatment of Chronic Wounds. Advances in wound care 2015, 4:560-582. 
3. Martinengo L, Yeo NJY, Markandran KDO, Olsson M, Kyaw BM, Car LT: Digital health professions education on chronic wound management: A systematic review. International Journal of Nursing Studies 2020, 104:103512.

4. Oladele HO, Fajemilehin RB, Oladele AO, Babalola EO: Health-related Quality of Life and Wound Care Practices Among Patients With Chronic Wounds in a Southwestern Nigerian Community. Wounds 2019, 31:127-131.

5. Martinengo L, Olsson M, Bajpai R, Soljak M, Upton Z, Schmidtchen A, Car J, Järbrink K: Prevalence of chronic wounds in the general population: systematic review and meta-analysis of observational studies. Annals of Epidemiology 2019, 29:8-15.

6. Green J, Jester R, McKinley R, Pooler A: The impact of chronic venous leg ulcers: a systematic review. Journal of Wound Care 2014, 23:601-612.

7. Olsson M, Järbrink K, Divakar U, Bajpai R, Upton Z, Schmidtchen A, Car J: The humanistic and economic burden of chronic wounds: A systematic review. Wound Repair and Regeneration 2019, 27:114-125.

8. Järbrink K, Ni G, Sönnergren H, Schmidtchen A, Pang C, Bajpai R, Car J: The humanistic and economic burden of chronic wounds: a protocol for a systematic review. Syst Rev 2017, 6:15.

9. Phillips CJ, Humphreys I, Fletcher J, Harding K, Chamberlain G, Macey S: Estimating the costs associated with the management of patients with chronic wounds using linked routine data. Int Wound J 2016, 13:1193-1197.

10. Sen CK, Gordillo GM, Roy S, Kirsner R, Lambert L, Hunt TK, Gottrup F, Gurtner GC, Longaker MT: Human skin wounds: a major and snowballing threat to public health and the economy. Wound Repair Regen 2009, 17:763-771.

11. Fearns N, Heller-Murphy S, Kelly J, Harbour J: Placing the patient at the centre of chronic wound care: A qualitative evidence synthesis. Journal of Tissue Viability 2017, 26:254-259.

12. Upton D, Upton P: Quality of Life and Well-Being. In Psychology of wounds and wound care in clinical practice. Springer; 2015: 85-111

13. Platsidaki E, Kouris A, Christodoulou C: Psychosocial Aspects in Patients With Chronic Leg Ulcers. Wounds 2017, 29:306-310.

14. Price P, Harding K: Cardiff Wound Impact Schedule: the development of a condition-specific questionnaire to assess health-related quality of life in patients with chronic wounds of the lower limb. International wound journal 2004, 1:10-17.

15. Deufert D, Graml R: Disease-specific, health-related quality of life (HRQoL) of people with chronic wounds-A descriptive cross-sectional study using the Wound-QoL. Wound Medicine 2017, 16:29-33.

16. Newbern S: Identifying Pain and Effects on Quality of Life from Chronic Wounds Secondary to Lower-Extremity Vascular Disease: An Integrative Review. Adv Skin Wound Care 2018, 31:102-108.

17. Aging and health [https://www.who.int/news-room/fact-sheet s/detai I/ageing-and-health.] 
18. Wounds International: Optimising wellbeing in people living with a wound. An expert working group review 2012.

\section{BATES-JENSEN WOUND ASSESSMENT TOOL}

[https://www.wwwoundcare.ca/Uploads/ContentDocuments/BWAT.pdf]

20. Granado-Casas M, Martinez-Gonzalez D, Martínez-Alonso M, Dòria M, Alcubierre N, Valls J, Julve J, Verdú-Soriano J, Mauricio D: Psychometric Validation of the Cardiff Wound Impact Schedule Questionnaire in a Spanish Population with Diabetic Foot Ulcer. Journal of Clinical Medicine 2021, 10:4023.

21. Bauer K, Rock K, Nazzal M, Jones O, Qu W: Pressure Ulcers in the United States' Inpatient Population From 2008 to 2012: Results of a Retrospective Nationwide Study. Ostomy Wound Manage 2016, 62:30-38.

22. Marola S, Ferrarese A, Solej M, Enrico S, Nano M, Martino V: Management of venous ulcers: State of the art. Int J Surg 2016, 33 Suppl 1:S132-134.

23. Goh OQ, Ganesan G, Graves N, Ng YZ, Harding K, Tan KB: Incidence of chronic wounds in Singapore, a multiethnic Asian country, between 2000 and 2017: a retrospective cohort study using a nationwide claims database. BMJ open 2020, 10:e039411.

24. Awad SF, Al-Mawali A, Al-Lawati JA, Morsi M, Critchley JA, Abu-Raddad LJ: Forecasting the type 2 diabetes mellitus epidemic and the role of key risk factors in Oman up to 2050: Mathematical modeling analyses. Journal of diabetes investigation 2021, 12:1162-1174.

25. Shidi A: Pressure ulcer management in Oman: Nurses' knowledge and views. Theses, Nursing and Health Care School, School of Medicine, College of Medical, Veterinary \& Life Science University of Glasgow, Scotlandia. Diakses dari http://theses. gla. ac. uk/7635/2/2016AlS hidiPhD. pdf; 2016.

26. Toscano CM, Sugita TH, Rosa MQ, Pedrosa HC, Rosa RdS, Bahia LR: Annual direct medical costs of diabetic foot disease in Brazil: a cost of illness study. International journal of environmental research and public health 2018, 15:89.

27. Vogt TN, Koller FJ, Dias Santos PN, Lenhani BE, Bittencourt Guimarães PR, Puchalski Kalinke L: Quality of life assessment in chronic wound patients using the Wound-QoL and FLQA-Wk instruments. Investigación y Educación en Enfermería 2020, 38.

28. Lentsck MH, Baratieri T, Trincaus MR, Mattei AP, Miyahara CTS: Quality of life related to clinical aspects in people with chronic wound. Revista da Escola de Enfermagem da USP 2018, 52.

29. Santos VLCdG, Oliveira AdS, Amaral AFdS, Nishi ET, Junqueira JB, Kim SHP: Quality of life in patients with chronic wounds: magnitude of changes and predictive factors. Revista da Escola de Enfermagem da USP 2017, 51.

30. McGinnis E, Briggs M, Collinson M, Wilson L, Dealey C, Brown J, Coleman S, Stubbs N, Stevenson R, Nelson EA: Pressure ulcer related pain in community populations: a prevalence survey. $B M C$ nursing 2014, 13:1-10.

31. Smith IL, Nixon J, Brown S, Wilson L, Coleman S: Pressure ulcer and wounds reporting in NHS hospitals in England part 1: audit of monitoring systems. Journal of tissue viability 2016, 25:3-15. 
32. Tariq G, Hamed J, George B, Cruz S, Jose J: Pressure ulcer prevalence and prevention rates in Abu Dhabi: an update. Journal of wound care 2019, 28:S4-S11.

33. Upton D, Upton P, Alexander R: The complexity of caring (Part 2): Moderators of detrimental health and well-being outcomes for caregivers of people with chronic wounds. Wound Practice \& Research: Journal of the Australian Wound Management Association 2015, 23:110-114.

34. Schunk M, Reitmeir P, Rückert-Eheberg I-M, Tamayo T, Schipf S, Meisinger C, Peters A, Scheidt-Nave C, Ellert $U$, Hartwig S: Longitudinal change in health-related quality of life in people with prevalent and incident type 2 diabetes compared to diabetes-free controls. PLoS One 2017, 12:e0176895.

35. Franks MM, Stephens MAP: Social support in the context of caregiving: Husbands' provision of support to wives involved in parent care. The Journals of Gerontology Series B: Psychological Sciences and Social Sciences 1996, 51:P43-P52.

36. Moeineslam M, Amiri P, Karimi M, Jalali-Farahani S, Shiva N, Azizi F: Diabetes in women and healthrelated quality of life in the whole family: a structural equation modeling. Health and Quality of Life Outcomes 2019, 17:178.

37. Santos JLGd, Erdmann AL, Peiter CC, Alves MP, Lima SBSd, Backes VMS: Comparison between the working environment of nurse managers and nursing assistants in the hospital context. Revista da Escola de Enfermagem da USP 2018, 51.

38. Upton P, Cartwright M, Upton D: Living with chronic wounds: an exploration of adaptive and maladaptive coping strategies and their association with wellbeing. Wounds international 2021, 12:12-17.

39. Robinson $\mathrm{H}$, Norton $\mathrm{S}$, Jarrett $\mathrm{P}$, Broadbent $\mathrm{E}$ : The effects of psychological interventions on wound healing: A systematic review of randomized trials. British Journal of Health Psychology 2017, 22:805-835.

\section{Tables}

Table 1. Demographic and clinical profile of the participants 
Demographic

Characteristics

\begin{tabular}{lllc}
\hline Age & \multicolumn{1}{c}{15 - 30 years } & 51 & 18.5 \\
\cline { 2 - 3 } & $31-45$ years & 87 & 31.6 \\
\cline { 2 - 3 } & $46-60$ years & 73 & 26.6 \\
\cline { 2 - 3 } Gender & Above 60 years & 64 & 23.3 \\
\hline Educational level & Male & 178 & 64.7 \\
\hline & Female & 97 & 35.3 \\
\hline
\end{tabular}

Marital status

Monthly Income

Occupation

Type of wound
Categories

Frequency

Percent

ra

$15-30 y e a$

Higher level (Higher secondary and above)

96

34.9

53

19.3

Unmarried

190

69.1

Married

12

4.4

Separated/Divorced

Widowed

20

7.2

less than 1000 riyals

244

88.7

Above 1000 riyals

31

11.3

Employed

102

37.1

Unemployed/student

69

Housewife

45

59

80

25.1

Pensioner

Diabetes ulcer

80

51

18.5

Pressure ulcers

51

61

22.2

Surgical wound ulcers

83

30.2

(Others) Traumatic , burn, arterial and venous ulcers 
Minimum 50

18.2

\begin{tabular}{llll}
\hline & Mild & 126 & 45.8 \\
\cline { 2 - 4 } & Moderate & 70 & 25.4 \\
\cline { 2 - 4 } $\begin{array}{l}\text { Presence of Co- } \\
\text { morbidities }\end{array}$ & Yes & 29 & 10.6 \\
\cline { 2 - 4 } & No & 187 & 68.0 \\
\hline Treatment & Medications and dressing & 88 & 32.0 \\
\cline { 2 - 4 } & Medication, dressing after wound debridement & 99 & 36.0 \\
\hline
\end{tabular}

Table 2. Perceived Wellbeing scores of the participants

\begin{tabular}{|c|c|c|c|c|c|}
\hline \multirow[t]{2}{*}{ Wellbeing Items } & \multicolumn{2}{|c|}{$\begin{array}{l}\text { Strongly disagree and } \\
\text { disagree }\end{array}$} & \multicolumn{2}{|c|}{$\begin{array}{l}\text { Agree and strongly } \\
\text { agree }\end{array}$} & \multirow[t]{2}{*}{$\begin{array}{l}\mathrm{p} \\
\text { value }\end{array}$} \\
\hline & Frequency & Percent & Frequency & Percent & \\
\hline I feel anxious about my wound & 88 & 32 & 187 & 68 & .000 \\
\hline $\begin{array}{l}\text { I feel frustrated at the time it is taking for } \\
\text { the wound to heal }\end{array}$ & 112 & 40.7 & 163 & 59.3 & .002 \\
\hline $\begin{array}{l}\text { I am confident that the wound I have will } \\
\text { heal }\end{array}$ & 235 & 85.5 & 40 & 14.5 & .000 \\
\hline $\begin{array}{l}\text { I worry that I may get another wound in } \\
\text { the future }\end{array}$ & 155 & 56.4 & 120 & 43.6 & .035 \\
\hline $\begin{array}{l}\text { The appearance of the wound site is } \\
\text { upsetting }\end{array}$ & 94 & 34.2 & 181 & 65.8 & .000 \\
\hline $\begin{array}{l}\text { I feel anxious about bumping the wound } \\
\text { site }\end{array}$ & 147 & 53.5 & 128 & 46.5 & .252 \\
\hline $\begin{array}{l}\text { I worry about the impact of the wound on } \\
\text { my family/ friends }\end{array}$ & 140 & 50.9 & 135 & 49.1 & .763 \\
\hline
\end{tabular}

Table 3. Association of wellbeing and satisfaction scores with the demographic and clinical profile of the participants 


\begin{tabular}{|c|c|c|c|c|c|c|}
\hline \multirow{2}{*}{$\begin{array}{l}\text { Demographic } \\
\text { characteristics }\end{array}$} & \multirow[t]{2}{*}{ Category } & \multirow[t]{2}{*}{$\mathrm{N}$} & \multirow{2}{*}{$\begin{array}{l}\text { Mean of wellbeing } \\
\text { scores }\end{array}$} & \multirow{2}{*}{$\begin{array}{l}\text { Std. } \\
\text { Deviation }\end{array}$} & & \\
\hline & & & & & $\begin{array}{l}\mathrm{F} / \mathrm{T} \\
\text { value }\end{array}$ & $\begin{array}{l}P \\
\text { value }\end{array}$ \\
\hline \multirow[t]{4}{*}{ Type of wound } & Diabetic ulcers & 80 & 10.14 & 1.914 & \multirow[t]{4}{*}{4.490} & \multirow[t]{4}{*}{.004} \\
\hline & Pressure ulcers & 51 & 11.16 & 1.391 & & \\
\hline & Surgical wounds & 61 & 10.11 & 1.790 & & \\
\hline & $\begin{array}{l}\text { Trauma, burn, } \\
\text { arterial and venous } \\
\text { ulcers }\end{array}$ & 83 & 10.63 & 1.846 & & \\
\hline \multirow[t]{2}{*}{$\begin{array}{l}\text { Educational } \\
\text { level }\end{array}$} & $\begin{array}{l}\text { Lower education } \\
\text { level }\end{array}$ & 179 & 10.64 & 1.813 & \multirow[t]{2}{*}{2.180} & \multirow[t]{2}{*}{.030} \\
\hline & $\begin{array}{l}\text { Higher education } \\
\text { levels }\end{array}$ & 96 & 10.15 & 1.777 & & \\
\hline \multirow[t]{3}{*}{ Gender } & Male & 178 & 10.25 & 1.819 & \multirow[t]{2}{*}{-2.711} & \multirow[t]{2}{*}{.007} \\
\hline & Female & 97 & 10.87 & 1.742 & & \\
\hline & & & $\begin{array}{l}\text { Mean scores of } \\
\text { satisfaction with } \\
\text { QOL }\end{array}$ & & & \\
\hline \multirow[t]{4}{*}{ Type of wound } & Diabetic ulcers & 80 & 7.40 & 2.138 & \multirow[t]{4}{*}{4.352} & \multirow[t]{4}{*}{.005} \\
\hline & Pressure ulcers & 51 & 5.90 & 2.617 & & \\
\hline & Surgical wounds & 61 & 6.89 & 2.388 & & \\
\hline & $\begin{array}{l}\text { Trauma, burn, } \\
\text { arterial and venous } \\
\text { ulcers }\end{array}$ & 83 & 7.01 & 2.330 & & \\
\hline
\end{tabular}

Table.4. Descriptive statistics and correlation between wellbeing, quality of life and satisfaction

\begin{tabular}{lllllll} 
Variable & $\mathrm{n}$ & $\mathrm{M}$ & $\mathrm{SD}$ & 1 & 2 & 3 \\
\hline How good is your quality? & 275 & 5.22 & 2.508 & - & & \\
\hline $\begin{array}{l}\text { How satisfied are you with your overall quality of } \\
\text { life? }\end{array}$ & 275 & 6.89 & 2.388 & $.440^{\star \star}$ & - \\
\hline Wellbeing Score & 275 & 10.47 & 1.813 & $-.282^{\star \star}$ & $-.300^{\star \star}$ & -
\end{tabular}

**. Correlation is significant at the 0.01 level (2-tailed). 
Figures

\section{Quality of life and satisfaction scores}

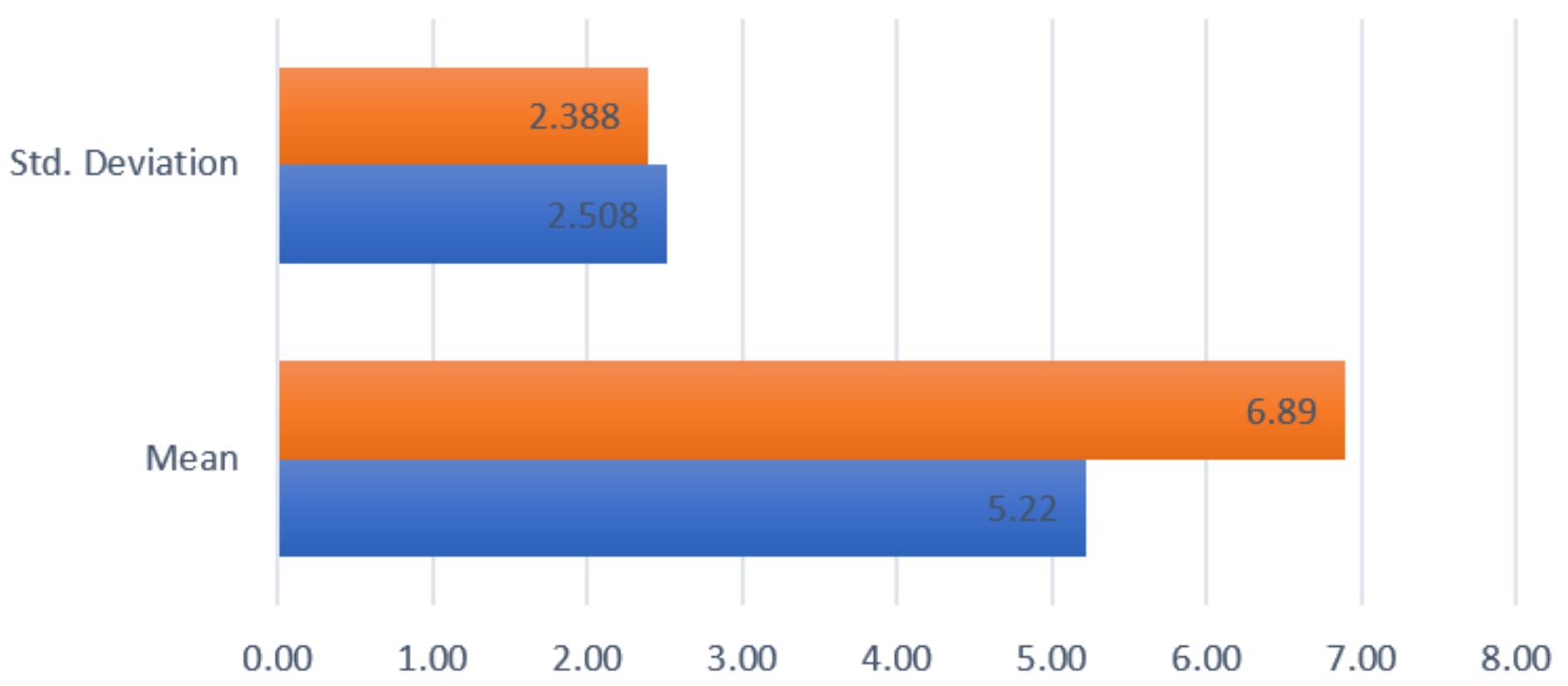

How satisfied are you with your overall quality of life? How good is your quality?

Figure 1

Mean and SD of Quality life and satisfaction scores as perceived by the patients 